\title{
Behavior of structural lightweight concrete produced with expanded clay aggregate and after exposure to high temperatures
}

\author{
Rita Nemes ${ }^{1} \cdot$ Mohammed A. Abed $^{2} \cdot$ Ahmed M. Seyam $^{1} \cdot$ Éva Lublóy $^{1}$ (D)
}

Received: 8 July 2021 / Accepted: 25 November 2021 / Published online: 30 December 2021

(C) The Author(s) 2021

\begin{abstract}
The residual compressive strength of eight lightweight concrete mixtures containing three commercial grading (Liapor HD $5 \mathrm{~N}$, Liapor HD $7 \mathrm{~N}$, and Liapor 8F) of coarse lightweight aggregate (LWA) were determined after to expose at high temperatures. Eight mixes were produced, two by normal weight aggregate and the rest by different types of LWA. The produced concrete was analyzed after high temperature exposure and the effect of using LWA, the type of LWA, and compaction method was studied. To do so, visual inspection, residual compressive strength, crack pattern, spalling, and thermoanalytical analysis were conducted. Generally, it could be concluded that concrete formulations with LWA behave more advantageous up to $500{ }^{\circ} \mathrm{C}$, compared to those with quartz gravel aggregates. Moreover, this study found that an ideal type of LWA to produce structural concrete was Liapor HD $5 \mathrm{~N}$, which was used for producing the mixes L1 and L3.
\end{abstract}

Keywords Lightweight aggregate $\cdot$ Lightweight aggregate concrete $\cdot$ High temperatures exposure $\cdot$ Expanded clay . Spalling $\cdot$ Thermoanalytical analysis

\section{Introduction and literature review}

The risk of concrete surfaces spalling is significantly higher in case of lightweight aggregate concrete (LWAC) structures compared to the conventional normal weight aggregate concrete (NWAC) structures. This could be attributed to three different causes [1-5]:

- Unequal heating of the cross-section due to different thermal conductivity coefficients between cement matrix and lightweight aggregate (LWA),

- Pressure induced by escaping water vapor from the moisture content of LWA,

- Different rates of thermal expansion between reinforcing steel and LWAC.

Éva Lublóy

lubloy.eva@epito.bme.hu

1 Department of Construction Materials and Technologies, Budapest University of Technology and Economics, Budapest 1521, Hungary

2 Department of Civil and Environmental Engineering, Rutgers University, Bartholomew Rd. 500, New Jersey 08854, USA
High temperature load design is required in the case of LWAC, where the knowledge and selection of the appropriate aggregate and its behavior are crucial. Changes to the strength characteristics of concrete under the impact of high temperature are largely determined by the type of aggregate used [6,7]. Figure 1 depicts how the type of aggregate strongly influences the behavior of concrete exposed to high temperatures [6]. Where the internal structure of the aggregate and the aggregate surface (different contact zones between aggregate and cement matrix) influence the behavior of concrete after exposure to high temperature. Therefore, in the case of LWAC, it has been suggested to use polypropylene fibers to avoid spalling of concrete cover [6].

No clear tendency of the compressive strength depend on the temperature can be identified on diagram Fig. 1.

Around $200{ }^{\circ} \mathrm{C}$, in the case of NWAC made with quartz gravel aggregates and limestone, an initial reduction in residual compressive strength was observed, followed by a transient increase of residual compressive strength. The different coefficients of thermal conductivity of cement matrix and aggregate could consider for the temporary loss of residual compressive strength $[8,9]$. Due to heat expansion of the cement matrix and aggregate, micro-cracks appear on the boundary surface of aggregate particles and the cement matrix. As temperature rises, these cracks close due to 


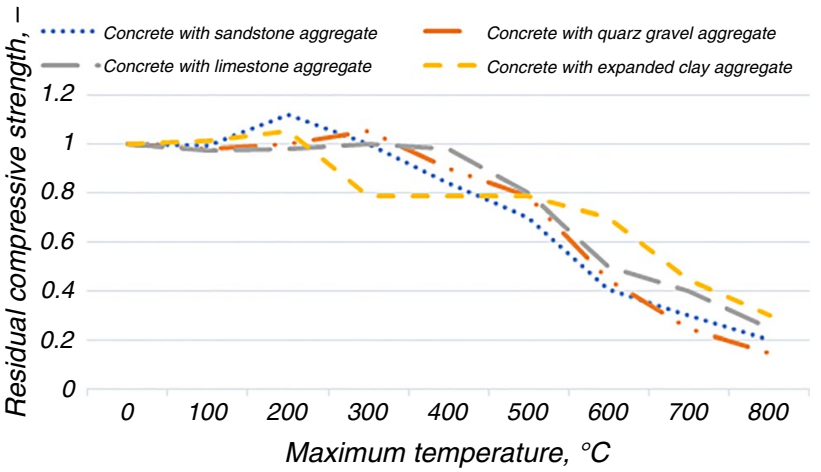

Fig. 1 Changing of residual compressive strength of concrete after high temperature exposure as a function of the type of the aggregate [6]

increasing heat expansion of the aggregate. Between 200 and $400{ }^{\circ} \mathrm{C}$, the residual compressive strength values decrease, and the observed reduction of strength may be explained by the cracking of the cement matrix. The change in strength of concrete with different types of aggregate must be discussed separately over $400{ }^{\circ} \mathrm{C}$ since it tends to differ significantly. The extent of the strength reduction in NWAC (quartz gravel aggregates, strength class from $\mathrm{C} 20 / 25$ to $\mathrm{C50/60)}$ ) is approximately $40 \%$ up to $550{ }^{\circ} \mathrm{C}$, which is more severe in the case of expanded clay aggregate, reaching about $20 \%$. Strength reduction in concrete exposed to temperatures between 450 and $550{ }^{\circ} \mathrm{C}$ is caused by the decomposition of portlandite, and the different heat expansion of aggregate and cement matrix.

The residual compressive strength of concrete after high temperature exposure is strongly influenced by how the load is transferred among the various components of the concrete. The way of load transfer depends on the strength and rigidity conditions relative to the individual components of the concrete [10]. Excessive stresses originating from the pressure are transferred through the components with higher strength and higher rigidity. The way of load transfer is substantially different in the case of concrete with quartz gravel aggregates and LWA, respectively. The compressive strength level of conventional concrete essentially comes from the aggregate strength, but it is limited by the strength and stability of the cement matrix (primarily water-to-cement ratio). In LWAC, the strength of the LWA is lower than the strength of the cement matrix. Compressive trajectories run in the cement matrix and get around the LWA $[11,12]$. The alteration of the load transfer mode is caused by the modulus of elasticity of the cement matrix and LWA that are more similar than those of quartz gravel aggregates and cement matrix. Due to the porous structure of the aggregate, the contact zone shows a substantially different structure in LWAC than in NWAC.

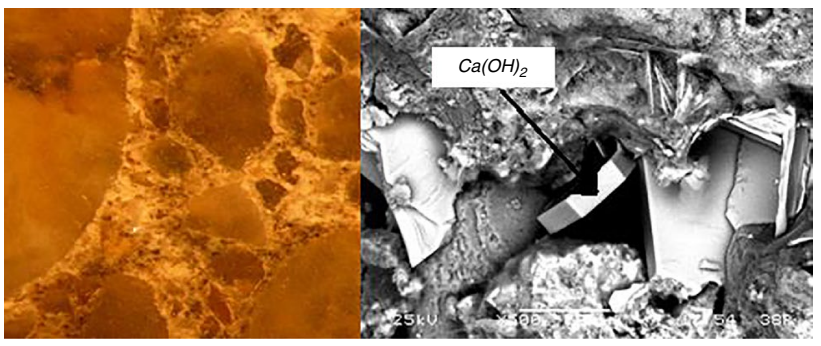

Fig. 2 Concrete with quartz gravel aggregate at $20{ }^{\circ} \mathrm{C}$ (optical and scanning electron microscopic images, to the left and right, respectively)

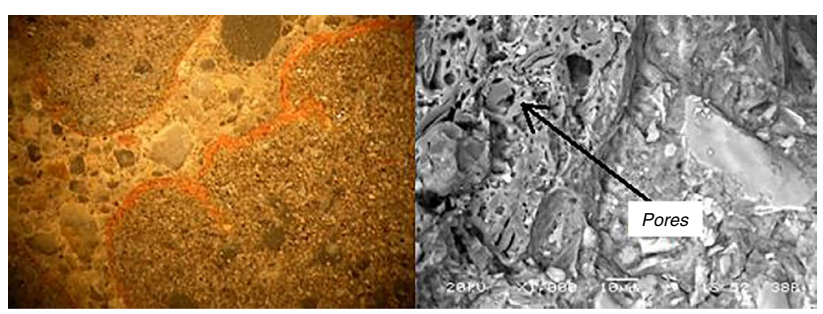

Fig. 3 The porous surface of the expanded clay aggregate

The layer of mortar mediates a great part of the load among the aggregate particles in NWAC, but load bearing is mainly considered as the function of aggregate particles [13]. NWAC usually damages upon heat load in the contact zone due to the difference between the modulus of elasticity of aggregate and the cement matrix. Figure 2 (left) shows an optical microscopic image of a quartz gravel aggregates. In the figure, the aggregate particles and the mortar parts are separated in the same sense. Figure 2 (right) shows an electron microscopic image of the same sample. It is clear from the image that portlandite (calcium hydroxide) and ettringite crystallized at the interface zone. Also, dehydration of the portlandite and ettringite layers is deposited on the surface of the aggregate. A thin water film is condensed on the surface of the aggregate and portlandite and ettringite minerals crystallize.

Figure 3 shows an optical and electron microscope image of the contact zone between LWA (expanded clay) and cement matrix. The aggregate surface has a significantly different surface area from the quartz gravel aggregates interface. LWA and the cement matrix merge into one another, becoming more delicate, creating a completely different kind of contact zone between the LWA and the cement matrix with conventional aggregate (Fig. 2).

The fresh cement matrix penetrates the pores of the aggregate surface with different amounts depending on the microscopic structure of the aggregate, cement fineness, and mortar consistency. Also, concrete compaction is affected by the behavior of concrete after high temperature exposure. 
The residual strength of self-compacting concrete (SCC) produced by different type of LWA (perlite, scoria, polystyrene) after exposure to high temperature was investigated by Aslani et al. [14]. Their study revealed that residual strength slightly increases with increasing temperature up to $450{ }^{\circ} \mathrm{C}$, but then decreases. The effect of high temperatures on highstrength SCC produced by LWA has been investigated. Their study concluded that maximum strength was achieved at $300{ }^{\circ} \mathrm{C}$, but upon reaching this temperature a major explosion occurred.

There are significant differences between the behavior of NWAC and LWAC after high temperature exposure. Therefore, the changes of the strength parameters of concrete prepared with the use of several various aggregates (quartz gravel aggregates to NWAC and expanded clay to LWAC) upon the impact of heat load were analyzed in the conducted experiments. Generally, the strength decrease of the LWAC is less than the strength decrease of NWAC after high temperature exposure. This could be explained by different contact zones (Figs. 2,3) and by different load-bearing systems (Fig. 1). In addition to a favorable strength development, it should be noted that LWA is porous, causing storage of water and moisture that increases the chance of spalling.

\section{Materials and methods}

The mixtures have been developed for various purposes with three different industrial aims. 1. series: Mix 1. (L1) and Mix 2. (L2) was investigate instead normal concrete C20/25 without special requirement (N1) what use highest amount in building construction industry. In this series, two types of LWA were tested, $5 \mathrm{~N}$, the lowest and 8F the highest strength expanded clay aggregate for load-bearing structures what is available in Hungarian market. Simple volumetric substitution was used but with increased cement content to recuse water-cement ratio. $5 \mathrm{~N}$ did not arrive the required strength class, $8 \mathrm{~F}$ has high strength but it is to expansive for building industry using. 2. series: Mix 3. (L3) is the optimization of L1 with lower cement and LWA amount. L3 is same compressive strength as reference concrete (N1), and the density remained below $2.0 \mathrm{~g} \mathrm{~mL}^{-1}$. Also tested when replaced with higher strength LWA (L4) and supplemented with fiber to increase the fire (L3F). 3. series: The aim of the 3 . series was a high-strength self-compacted lightweight aggregate concrete (L5) with the highest strength expanded clay aggregate and used same composition as a reference high-strength self-compacted concrete (N2). Although these presented compositions are not a part of an experimental series, they are successive developments may conclusions can be drawn. They are all made for building structure, so they all have a fire resistance requirement.
Eight mixes were produced; river quartz aggregate was used as a reference aggregate for producing mixes N1 and N2. Table 1 shows the properties of the LWA. The expanded clay aggregates were:

- Liapor HD $5 \mathrm{~N}$; it is a conventional LWA and was used for producing the mixes: $\mathrm{L} 1, \mathrm{~L} 3$, and $\mathrm{L} 3 \mathrm{~F}$,

- Liapor HD $7 \mathrm{~N}$; it is a high-strength LWA and was used for producing the mix: $\mathrm{L} 4$,

- Liapor 8F; it is a high-strength LWA was used for producing the mixes: L2 and L5.

Two types of cement were used. N1, L1, L2, N2, and L5 mixtures were prepared with CEM I $42.5 \mathrm{~N}$ while, L3, L4, and L3F mixes were prepared with CEM I $52.5 \mathrm{~N}$. N1, L1, L2, L3, L4, L3F are concretes with compaction, while N2 and L5 are self-compacted concrete. The composition of the mixtures is proposed in Table 2. Compressive strength of mixtures (average value of 3 specimens) without heating processes is presented in Fig. 4.

Standard compressive strength test was carried out according to EN 12,390-3 (load speed $11.250 \mathrm{kNs}^{-1}$ ), and the tested specimens were standard cubes (edge length $150 \mathrm{~mm}$ ) [15]. The 28 days specimens before compressive strength tests were heated according the standard heating curve and cooling for $24 \mathrm{~h}$. The mode and speed of the heat loading are important issues after high temperature load tests. In the present experiments, a normative heating curve to the standard heating curve proposed in EN 1991-1-2 [16], which is similar to the fire curves applicable to structural engineering (Fig. 5).

After demolding the specimens, they were placed under water for seven days, then stored in a laboratory at room temperature $\left(20^{\circ} \mathrm{C}, 65 \%\right.$ relative humidity) until the heat load was applied (28 days) as recommended by EN 206-1 [17]. Test specimens were kept at different temperature levels for two hours $\left(20^{\circ} \mathrm{C}, 50{ }^{\circ} \mathrm{C}, 150{ }^{\circ} \mathrm{C}, 200{ }^{\circ} \mathrm{C}, 300{ }^{\circ} \mathrm{C}\right.$, $400{ }^{\circ} \mathrm{C}, 500{ }^{\circ} \mathrm{C}, 600{ }^{\circ} \mathrm{C}$, and $800{ }^{\circ} \mathrm{C}$, respectively), then cooled down to laboratory temperature for $24 \mathrm{~h}$, and the residual compressive strength was measured in all combination 3 specimens parallel.

Table 1 Properties of the applied lightweight aggregates

\begin{tabular}{llll}
\hline $\begin{array}{l}\text { LWA } \\
\text { (expanded clay) }\end{array}$ & $\begin{array}{l}\text { Particle } \\
\text { size/mm }\end{array}$ & $\begin{array}{l}\text { Particle den- } \\
\text { sity/kgm }\end{array}$ & $\begin{array}{l}\text { Water absorption } \\
\text { after 24 h/\% by } \\
\text { mass }\end{array}$ \\
\hline Liapor HD 5 N & $4 / 8$ & 1047 & 18 \\
Liapor HD 7 N & $4 / 8$ & 1185 & 13 \\
Liapor 8F & $4 / 8$ & 1380 & 13 \\
\hline
\end{tabular}


Table 2 Composition of the tested concretes

\begin{tabular}{|c|c|c|c|c|c|c|c|c|}
\hline Mixtures & N1 & L1 & L2 & L3 & L4 & L3F & $\mathrm{N} 2$ & L5 \\
\hline CEM I $42.5 \mathrm{~N}, \mathrm{kgm}^{-3}$ & 350 & 460 & 460 & - & - & - & 500 & 500 \\
\hline CEM I $52.5 \mathrm{~N}, \mathrm{kgm}^{-3}$ & - & - & - & 386 & 386 & 386 & - & - \\
\hline Water, $\mathrm{kgm}^{-3}$ & 151 & 160 & 160 & 181 & 181 & 181 & 175 & 175 \\
\hline Water-to-cement ratio, - & 0.43 & 0.35 & 0.35 & 0.47 & 0.47 & 0.47 & 0.35 & 0.35 \\
\hline Quartz sand (up to $4 \mathrm{~mm}$ ), $\mathrm{kgm}^{-3}$ & 912 & 622 & 754 & 1024 & 1015 & 1024 & 785 & 785 \\
\hline Quartz aggregate ( 4 to $8 \mathrm{~mm}$ ), $\mathrm{kgm}^{-3}$ & 485 & - & - & - & - & - & 960 & - \\
\hline Quartz aggregate (8 to $16 \mathrm{~mm}$ ), $\mathrm{kgm}^{-3}$ & 544 & - & - & - & - & - & - & - \\
\hline Expanded clay LWA (4 to $8 \mathrm{~mm}$ ), $\mathrm{kgm}^{-3}$ & - & 533 & 552 & 302 & 390 & 302 & - & 464 \\
\hline Expanded clay LWA (type) & - & $(5 \mathrm{~N})$ & $(8 \mathrm{~F})$ & $(5 \mathrm{~N})$ & $(7 \mathrm{~N})$ & $(5 \mathrm{~N})$ & - & $(8 \mathrm{~F})$ \\
\hline Superplasticizer, $\mathrm{kgm}^{-3}$ & 1.4 & 1.15 & 1.15 & 5 & 5 & 5 & 1.5 & 6 \\
\hline $\begin{array}{l}\text { Polypropylene fiber, } \mathrm{kgm}^{-3} \\
(\varnothing=0.0032 \mathrm{~mm}, 1=18 \mathrm{~mm})\end{array}$ & - & - & - & - & - & 1 & - & - \\
\hline Density of fresh concrete, $\mathrm{kgm}^{-3}$ & 2443 & 1776 & 1927 & 1898 & 1977 & 1899 & 2322 & 1930 \\
\hline Average compressive strength, $\mathrm{Nmm}^{-2}$ & 43.5 & 27.5 & 53.2 & 36.1 & 46.3 & 34.5 & 78.0 & 56.0 \\
\hline
\end{tabular}

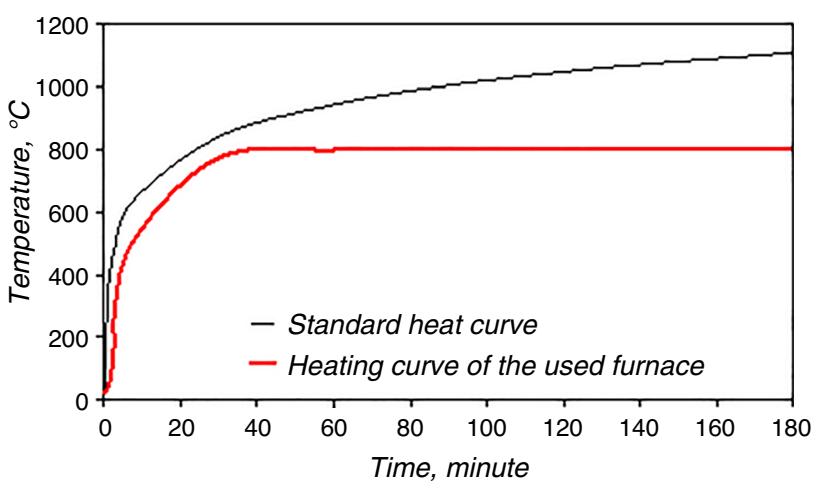

Fig. 5 Heating up curve used in the experiments and the standard heating curve

\section{Crack pattern analysis}

Test specimens were cooled down after heat load to room temperature and tested (compressive strength test), then the crack pattern was analyzed. Test specimens made of higher strength aggregate $(7 \mathrm{~N}, 8 \mathrm{~F})$ showed a crack pattern seen in Fig. 8 (left) in the compressive strength test following a heat load up to $500{ }^{\circ} \mathrm{C}$. The specimens made of lower strength aggregate $(5 \mathrm{~N})$ showed different crack pattern (Fig. 8 right) Fracturing of cracked aggregate particles could be due to the strength of expanded clay aggregate, which is lower than the cement matrix. Following the $500{ }^{\circ} \mathrm{C}$ heat load, the fractured surface became nearly vertical, it was observed that the contact zone surface of the aggregate, and cement matrix changed upon heat load impact.

Test specimens with $5 \mathrm{~N}$ aggregate provided the fracture pattern shown in Fig. 9 in the compressive test made after the $800{ }^{\circ} \mathrm{C}$ heat load. After the test, it was observed LWA particles cracked and partly dropped out. It is likely 


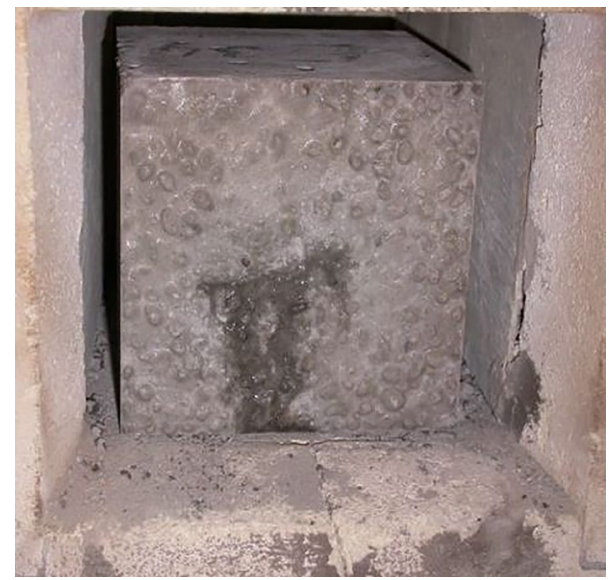

Fig. 6 Evaporation from LWAC specimens after the temperature loading of $300{ }^{\circ} \mathrm{C}$

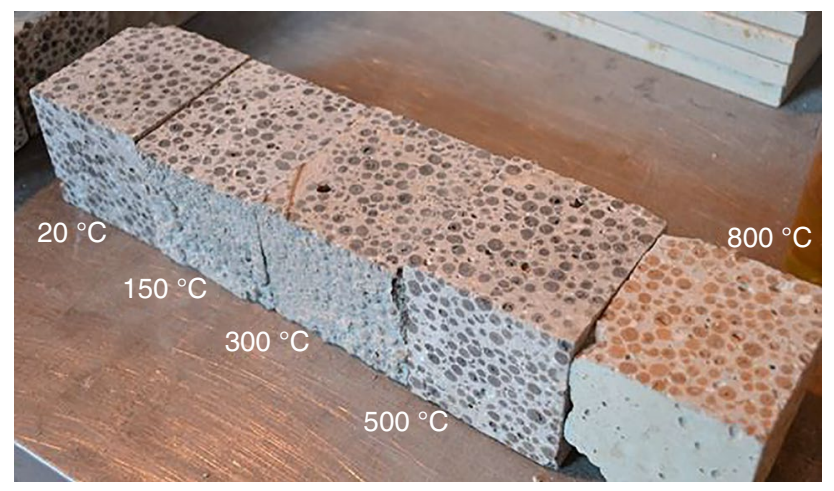

Fig. 7 Color scale of specimens made of expanded clay aggregate Liapor HD $5 \mathrm{~N}$

that this occurred because the strength of the expanded clay aggregate after heat load is approximately equal to the compressive strength of the cement matrix. The strength of the expanded clay aggregate under heat load did not change as it was manufactured at a high temperature $\left(1100-1200^{\circ} \mathrm{C}\right)$. But the strength of the cement matrix was reduced under heat load. After $800{ }^{\circ} \mathrm{C}$ heat load, the specimen showed a pyramid-like fracture pattern, and collapse of the cement matrix was seen.

\section{Residual compressive strength}

The residual compressive strength values are provided in Figs. 10, 11, 12 in different comparison. These values have to be derived by dividing the compressive strength value measured after a given heat load with the strength at $20^{\circ} \mathrm{C}$, obtaining the extent of strength reduction in percentage. The average residual compressive strength (after heat load and

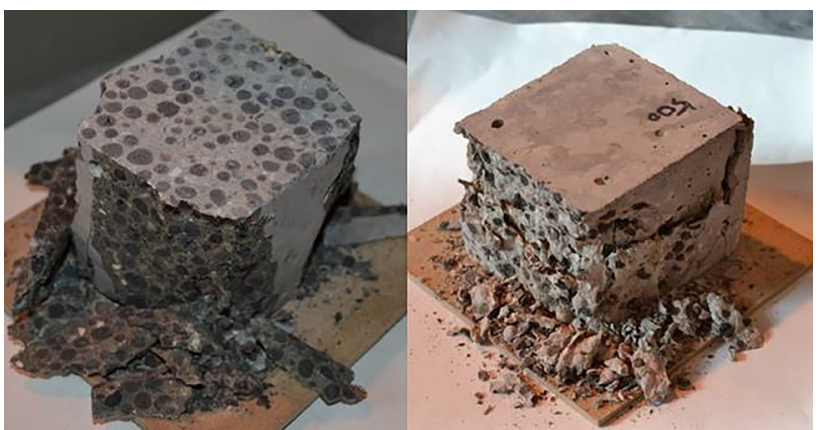

Fig. 8 Expanded clay aggregate test specimens after compressive tests: Liapor $8 \mathrm{~F}$ aggregate concrete, L2 (left), and Liapor HD $5 \mathrm{~N}$ aggregate concrete, L1 (right) after high temperature exposure up to $500{ }^{\circ} \mathrm{C}$

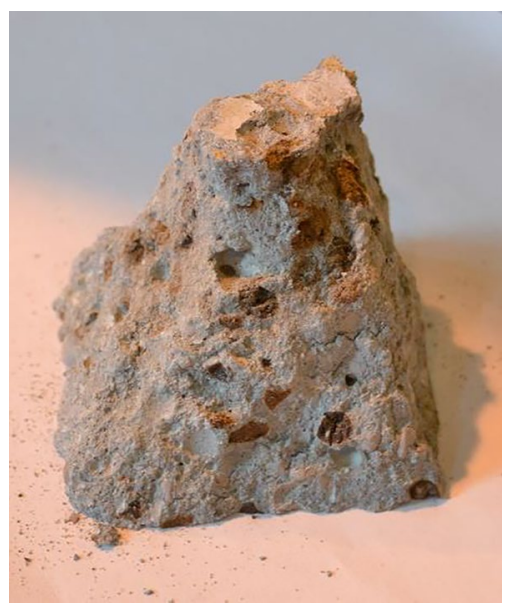

Fig. 9 Liapor HD $5 \mathrm{~N}$ aggregate concrete specimen (M1) of compressive strength test after heat load up to $800{ }^{\circ} \mathrm{C}$

cooling to room temperature) is discussed in the following sections in terms of the effect of LWA, LWA type, and compaction method.

\section{Effect of the amount of lightweight aggregate}

The residual compressive strength results of NWAC and LWAC are shown in Fig. 10. The LWA amount in mix L1 is $50 \%$ by volume, and in mix L3 and L3F is only $30 \%$. By comparing the residual compressive strength after the heating process, an increase was observed in the residual strength of LWAC after a heat load of $150{ }^{\circ} \mathrm{C}$ compared to NWAC. Conventional LWAC (e.g., Liapor $5 \mathrm{~N}$ ) is highly porous. These open pores could contain water that evaporates at temperatures over $100{ }^{\circ} \mathrm{C}$. After a higher temperature load in the case of the same compressive strength class, the behavior of NWAC is similar to LWAC. When the LWA content is higher, the residual compressive strength is also 


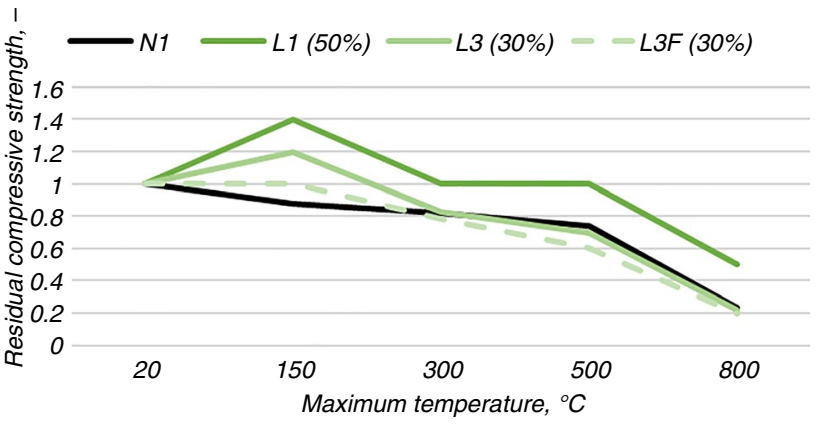

Fig. 10 Residual compressive strength of NWAC and conventional LWAC with Liapor HD $5 \mathrm{~N}$

higher. Higher strength was measured in concretes with Liapor HD $5 \mathrm{~N}$ aggregate (L1, L3, and L3F) following a heat load of $150{ }^{\circ} \mathrm{C}$ than at room temperature. This could be explained by the high-water absorption capacity of the aggregate.

After $150{ }^{\circ} \mathrm{C}$, the evaporation of water stored in the aggregate increased the residual compressive strength of the concrete. Beyond $300^{\circ} \mathrm{C}$, a gradual decrease in compressive strength could be observed. This is nearly the same as the one measured at $20{ }^{\circ} \mathrm{C}$. In the case of LWAC, the ratio of the initial strength to the residual strength measured after $800{ }^{\circ} \mathrm{C}$ exposure is more favorable than that of the NWAC. This may be due to its high porosity level (67\%) and the open-pore structure of the aggregate. The type of LWA was same in this series but the amount of LWA was in mix L1 is with $75 \%$ higher, than in L3 and L3F. The higher LWA content was more favorable even with a lower water-cement ratio. This effect is particularly significant above $300^{\circ} \mathrm{C}$. L3 reacted more sensitively to heat, largely resulting from the different types of cement and cement volumes. However, L3F responded to the increase of temperature more significantly than did mix L3. This result follows from the addition of polypropylene fibers, the effect of PP microfibers with LWA application is different than with NWA. In the case of a porous aggregate, the addition of $1 \%$ of PP fiber does not increase the residual compressive strength (L3 and L3F).

\section{Effect of lightweight aggregate type}

The correlation between residual compressive strength and temperature is illustrated in Fig. 11 in the case of conventional $(5 \mathrm{~N})$ and high-strength $(7 \mathrm{~N}$ and $8 \mathrm{~F})$ types of expanded clay aggregate. L2 and L4 are prepared using higher strength aggregates and initially show similar compressive strength reduction as NWC. Residual compressive strength reflected a nearly permanent level between 150 and $500{ }^{\circ} \mathrm{C}$, there was no increase at $150{ }^{\circ} \mathrm{C}$ than in case of the conventional LWA $(5 \mathrm{~N})$. Due to heat deformation of the cement matrix, aggregate micro-cracks formed on

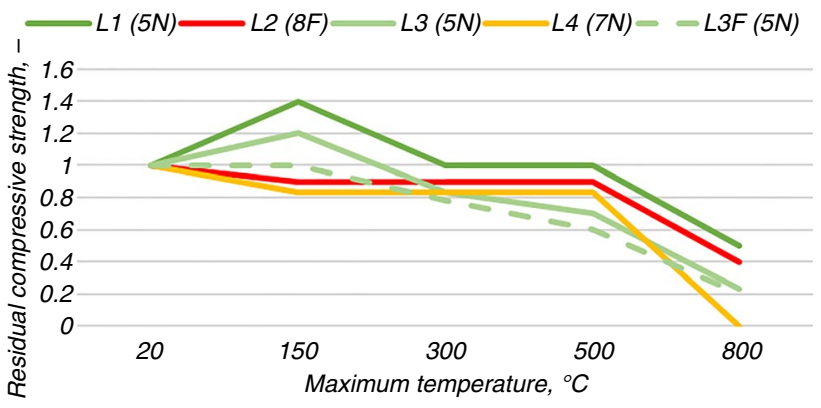

Fig. 11 Residual compressive strength of different LWAC mixtures

the contact surface of the aggregate particles and cement matrix while the residual compressive strength is decreased up to $500{ }^{\circ} \mathrm{C}$. The reduction of compressive strength up to $500{ }^{\circ} \mathrm{C}$ reached approximately $20 \%$. Such impaired strength is caused by the decay of portlandite between 450 and $550{ }^{\circ} \mathrm{C}$, and the different heat dilatation of the aggregate and cement matrix. Further reduction in strength was observed beyond $500{ }^{\circ} \mathrm{C}$, caused by the transformation of the C-S-H compounds. Above $500{ }^{\circ} \mathrm{C}$, the strength of the NWC decreases because the quartz has changes in volume (in 573 and $867^{\circ} \mathrm{C}$ ). The firing temperature of expanded clay aggregate under the manufacturing is $1200{ }^{\circ} \mathrm{C}$ that can be the reason of the better behavior of LWAC above $500{ }^{\circ} \mathrm{C}$. This is only true if the LWA is completely swollen during the manufacturing. If it is not complete, there is a gradual increase in volume under the heat treatment which crack the specimen. This volume changing of LWA was observed at the highest strength LWA type (8F). After a heat load of $800{ }^{\circ} \mathrm{C}$, the test specimens of mix L2 was destroyed, the residual compressive strength was taken as zero.

It could be concluded that the concrete formulations with LWA behave optimally up to $500{ }^{\circ} \mathrm{C}$ than those with quartz gravel aggregates. The most preferable LWA type was Liapor HD $5 \mathrm{~N}$ (L1) while the least favorable was Liapor $8 \mathrm{~F}$ (L2). The most important difference was in aggregate porosity, where higher porosity is favorable under fire. The residual compressive strength of concrete is influenced by the way the load is transferred among the various constituent parts of concrete. The mode of load transfer depends on the strength and rigidity conditions to the individual constituent parts of concrete. Excessive stresses originating from pressure are transferred throughout the components with higher strength and higher rigidity levels. The layer of mortar mediates a great part of the load among aggregate particles in conventional LWAC, but in case of high-strength LWA, the trajectories go through the aggregates particles.

NWAC collapses upon heat load in the contact zone, caused by the difference between the modulus of elasticity of aggregate and cement matrix, respectively, as well as the dehydration of the portlandite and ettringite layers 


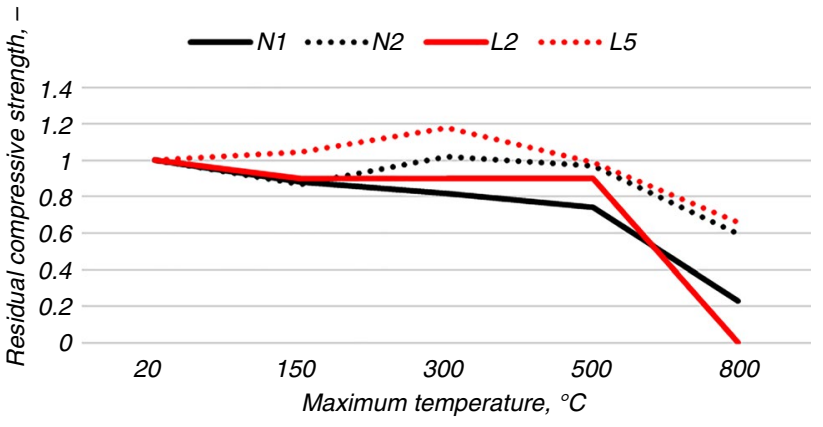

Fig. 12 Residual compressive strength of normal compacted and selfcompacted concretes with quartz and expanded clay aggregate

deposited on the surface of the aggregate. A thin water film condenses on the surface of the aggregate, thus portlandite and ettringite crystallize built there. Compressive trajectories run through the aggregate particles and in the cement matrix and avoided the LWA. The behavior of high-strength concrete is different: the calcium hydroxide reacts with silica powder and calcium silica-hydrate forms, which increases the strength of build layer in the contact zone deposited on the surface of aggregate particles. Therefore, the typical location of collapse in high-strength concrete is not the contact zone but the aggregate where split of the aggregate particles can happen.

\section{Effect of compaction method}

Conventional compacted and self-compacted concretes with normal and lightweight aggregate were compared. Mix N2 was a self-compacted high-strength concrete (SCHSC), and mix L5 has same cement mortar matrix with high-strength expanded clay aggregate (Tables 1 and 2.). Figure 12 shows the results of residual compressive strength.

Behavior of conventional and SCHS concrete from residual compressive strength aspect are similar until $500{ }^{\circ} \mathrm{C}$. In case of higher temperature, the SCHSC is favorable, SCHSC do not loss the strength until $500{ }^{\circ} \mathrm{C}$. The reason is the ideal pore structure that come from self-compaction method. This effect from compaction method combined with the pore system of the lightweight aggregate is more favorable, and it is observable over $500{ }^{\circ} \mathrm{C}$, too.

\section{Summary and conclusions}

This study aims to assess the residual compressive strength of the load-bearing lightweight concrete (LC16/18-LC40/44) after heat load in case of using different expanded clay aggregates. During the test series, the gravel fraction (higher than $4 \mathrm{~mm}$ ) of the normal weight aggregate has been replaced by lightweight aggregate (LWA), namely Liapor HD $5 \mathrm{~N}$, Liapor HD $7 \mathrm{~N}$ or Liapor 8F. Considerate heat load design is needed when applying lightweight aggregate concrete, meanwhile selection of the appropriate aggregate and knowledge of its behavior is crucial. Three different LWA products have been tested in addition to normal quartz gravel aggregates in seven concrete mixtures and at nine heat load levels $\left(20{ }^{\circ} \mathrm{C}, 50{ }^{\circ} \mathrm{C}, 150{ }^{\circ} \mathrm{C}, 200{ }^{\circ} \mathrm{C}, 300{ }^{\circ} \mathrm{C}, 400{ }^{\circ} \mathrm{C}, 500{ }^{\circ} \mathrm{C}\right.$, $600{ }^{\circ} \mathrm{C}$, and $800^{\circ} \mathrm{C}$ ).

Based on our research results, the following results can be obtained on the structural lightweight concrete with expanded clay aggregates in terms of fire resistance.

- If in conventional load-bearing concrete, the quartz gravel is replaced by the same volume percentage of expanded clay applying the same cement mortar matrix (mix N1 $\rightarrow \mathrm{L} 3$ ), the compressive strength on $20{ }^{\circ} \mathrm{C}$ decreases but the relative residual compressive strength after heat loading is favorable. Bellow $300{ }^{\circ} \mathrm{C}$, the use of LWA increased the residual strength, which can be explained by the lower pressure of water vapor due to the high porosity of the aggregate. Between 300 to $800{ }^{\circ} \mathrm{C}$, expanded clay and normal aggregate concrete behaved similarly.

- When $1 \%$ by volume PP fiber is used in LWAC (mix $\mathrm{L} 3 \rightarrow \mathrm{L} 3 \mathrm{~F}$ ), it slightly reduces the compressive and the relative residual compressive strength between 150 and $800{ }^{\circ} \mathrm{C}$, too. The reason for the addition of PP fiber in NWC is that after the fibers melt there remains enough pores for water vapor. However, in case of (a sufficiently high porosity) LWA the porosity is higher than it is achieved by the fibers, thus the fibers do not cause any positive effect in LWAC.

- In the case of increasing LWA amount from 30 to $50 \%$ and higher strength mortar matrix (higher cement amount and lower water-cement ratio), the compressive strength on $20^{\circ} \mathrm{C}$ was lower but the relative residual compressive strength was higher between 150 and $800{ }^{\circ} \mathrm{C}$. At $800{ }^{\circ} \mathrm{C}$, the compressive strength of LWAC with 50\% LWA content (mix L1) is twice that compressive strength of NWC (mix N1).

- If the generally used LWA is replaced with a highstrength type of LWA (lower porosity, more closed surface) and used in the same volume then the behavior of LWAC up to $300{ }^{\circ} \mathrm{C}$ is similar to NWC. The local maximum value of the relative residual compressive strength in $150{ }^{\circ} \mathrm{C}$ was not observed. Between 300 and $500{ }^{\circ} \mathrm{C}$, high-strength LWAC shows a more favorable characteristic than NWC, typically LWAC behavior. This is also true when used with normal or increased compressive strength cement mortar. At $800{ }^{\circ} \mathrm{C}$, the concrete was destroyed using a high-strength LWA and 
normal strength cement mortar together. The swelling of the aggregate, which was not fully swollen during the manufacturing, cracked the concrete (L2). This is similar situation when the quartz gravel swells at $573{ }^{\circ} \mathrm{C}$ due to the crystal transformation and destroys the cement mortar. By increasing the strength of the cement mortar or decreasing the strength of LWA, this deterioration can be avoided (L3).

- In case of replacing the quartz gravel by expanded clay in high-strength self-compacted concrete, the compressive strength decreases at $20^{\circ} \mathrm{C}$, but LWAC behaves significantly more favorable between 150 and $800{ }^{\circ} \mathrm{C}$ than NWC. Self-compacted concrete was more favorable with both NWA and LWA than the conventional compacted variants. This is due to the ideally distributed pore structure in the cement matrix.

- When self-compacted mode and the high-strength expanded clay aggregate are used together, the advantages of both effects can be exploited from the fire resistance aspect. High-strength expanded clay aggregate shall not be used if the pore structure of the cement mortar matrix is not ideal and the strength of the matrix is not sufficient. The swelling of the aggregate in high temperature (about $800^{\circ} \mathrm{C}$ ) causes destruction of not enough strength concrete.

Funding Open access funding provided by Budapest University of Technology and Economics. The authors are thankful for the support of the research received through the project GINOP-2.1.2-8-1-4-16. The research reported in this paper is part of project no. BME-NVA-02, implemented with the support provided by the Ministry of Innovation and Technology of Hungary from the National Research, Development and Innovation Fund, financed under the TKP2021 funding scheme.

Data availability All data, models, and code generated or used during the study appear in the submitted article.

Open Access This article is licensed under a Creative Commons Attribution 4.0 International License, which permits use, sharing, adaptation, distribution and reproduction in any medium or format, as long as you give appropriate credit to the original author(s) and the source, provide a link to the Creative Commons licence, and indicate if changes were made. The images or other third party material in this article are included in the article's Creative Commons licence, unless indicated otherwise in a credit line to the material. If material is not included in the article's Creative Commons licence and your intended use is not permitted by statutory regulation or exceeds the permitted use, you will need to obtain permission directly from the copyright holder. To view a copy of this licence, visit http://creativecommons.org/licenses/by/4.0/.

\section{References}

1. Lindgård J, Hammer TA. Fire resistance of structural lightweight aggregate concrete a literature review survey with focus on spalling, supplementary papers. In: Proceedings of 4th CANMET/ $\mathrm{ACI} / \mathrm{JCI}$ international conference on recent advances in concrete technology. 1998;25-39.

2. Tanyildizi H, Coskun A. Performance of lightweight concrete with silica fume after high temperature. Constr Build Mater. 2008;22:2124-9. https://doi.org/10.1016/j.conbuildmat.2007.07. 017.

3. Copier WJ. The spalling of normal weight and lightweight concrete exposed to fire. Spec Publ. 1983;80:219-36.

4. Debicki G, Haniche R, Delhomme F. An experimental method for assessing the spalling sensitivity of concrete mixture submitted to high temperature. Cem Concr Compos. 2012. https://doi.org/10. 1016/j.cemconcomp.2012.04.002.

5. Faust T. Leichtbeton im konstruktiven Ingenieurbau. Wiley; 2003. (in German).

6. Schneider U. Properties of materials at high temperatures - concrete, RILEM Report. 1986.

7. Khoury GA, et al. Fire design of concrete materials structures and modelling. In: 1st fib Congress, Osaka, Japan, 2001.

8. Hinrichsmeyer K. Structure-oriented analysis and model description of thermal damage to concrete. 1987.

9. Abed M, Nemes R, Lublóy É. Performance of self-compacting high-performance concrete produced with waste materials after exposure to elevated temperature. J Mater Civ Eng. 2020. https:// doi.org/10.1061/(ASCE)MT.1943-5533.0002989.

10. Cui HZ, Lo TY, Memon SA, Xu W. Effect of lightweight aggregates on the mechanical properties and brittleness of lightweight aggregate concrete. Constr Build Mater. 2012. https://doi.org/10. 1007/s13369-014-1023-9.

11. Ujhelyi J, Betonismeretek (Knowledge of Concrete), Múegyetemi Kiadó, ISBN 9634208339. 2005. (in Hungarian)

12. Koksal F, Gencel O, Brostow W, Lobland HH. Effect of high temperature on mechanical and physical properties of lightweight cement based refractory including expanded vermiculite. Mater Res Innov. 2012. https://doi.org/10.1179/1433075X11Y.00000 00020.

13. Zhang MH, Gjørv OE. Microstructure of the interfacial zone between lightweight aggregate and cement paste. Cem Concr Res. 1990;20:610-8.

14. Aslani F, Ma G. Normal and high-strength lightweight self-compacting concrete incorporating perlite, scoria, and polystyrene aggregates at elevated temperatures. J Mater Civ Eng. 2018;30:12. https://doi.org/10.1061/(ASCE)MT.1943-5533.0002538.

15. EN 12390-3. Testing hardened concrete - Part 3: Compressive strength of test specimens. 2019.

16. EN 1991-1-2. Actions on structures - Part 1-2: General actions Actions on structures exposed to fire. 1991.

17. EN 206-1. Concrete. Specification, performance, production and conformity. 2000.

Publisher's Note Springer Nature remains neutral with regard to jurisdictional claims in published maps and institutional affiliations. 